EESTI NSV TEADUSTE AKADEEMIA TOIMETISED. GEOLOOGIA

ИЗВЕСТИЯ АКАДЕМИИ НАУК ЭСТОНСКОИ ССР. ГЕОЛОГИЯ

PROCEEDINGS OF THE ACADEMY OF SCIENCES OF THE ESTONIAN SSR. GEOLOGY $1984,33,2$

\title{
О СТРАТИГРАФИЧЕСКОЙ СХЕМЕ РАСЧЛЕНЕНИЯ КУКРУЗЕСКОГО ГОРИЗОНТА В СТРАТОТИПИЧЕСКОЙ ОБЛАСТИ
}

В результате проведенных за последние два-три десятилетия различных геологических работ накоплена обширная новая информация о строении кукрузеского горизонта в стратотипической области, которая, однако, в публикациях практически не отражена. Новые материалы о геологии, в частности о стратиграфии и особенно микростратиграфии сланценосных отложений рассматриваемого горизонта, нуждаются в обобщении. В связи с этим представляется крайне актуальным рассмотрение недавно формально установленной (Решения..., 1978; Мянниль, Рыымусокс, 1984) местной стратиграфической схемы расчленения кукрузеских отложений на конкретном материале. Цель настоящей статьи - конкретизация указанной местной, стратотипической схемы на примере увязки ее с некоторыми ранее известными по публикациям буровыми разрезами и сопоставления на этой основе с ранее предложенными схемами расчленения горизонта. Можно надеяться, что это наилучшим образом раскроет суть местной схемы и будет содействовать единому пониманию и дальнейшему детальному описанию ее подразделений.

Для конкретного рассмотрения вопросов стратиграфии кукрузеского горизонта в данной статье используются разрезы трех буровых скважин - Савала, Тыкке и Камарику, первая из которых расположена в районе Кивиыли, вблизи южной границы выходов кукрузеского горизонта (Эстонское месторождение горючих сланцев), а две остальные на юге, примерно в 40 км от выходов (Тапаское месторождение) (рис. 1). Скв. Савала (Мянниль, 1966, рис. 11, 16, 17) пробурена Институтом геологии АН ЭССР со стратиграфической целью и ее керн можно рассматривать как гипостратотипический разрез ухакуского и

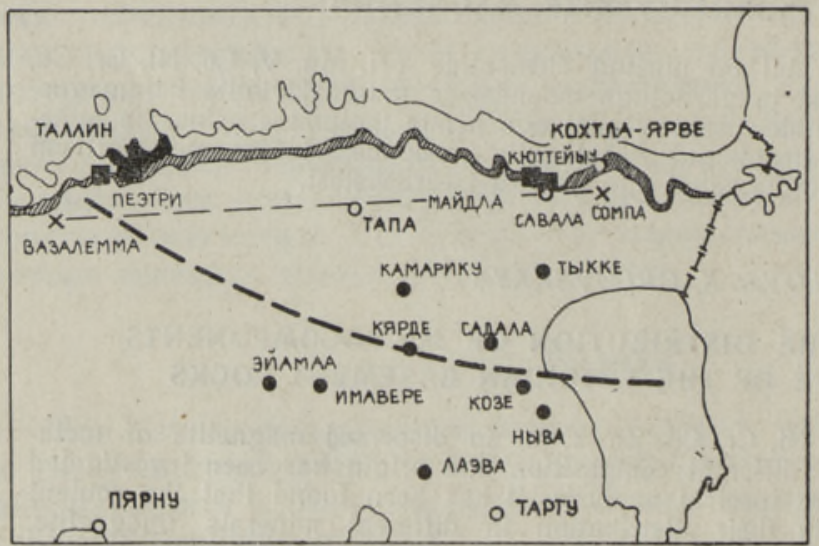

Рис. 1. Схема расположения обнажений и буровых скважин. $I$ полоса выхода кукрузеского горизонта (северная эрозионная граница распространения отложений), 2 условная южная граница бассейна горючнх сланцев, одновременно показывающая простирание отложений с одинаковой стратиграфнческой полнотой их развития, 3 обнажение, 4 буровая скважина, 5 линия схематичного профиля, прнведенного на рис. 3 . 
кукрузеского горизонтов. Разрез кукрузеского горизонта в этой скважине практически идентичен его разрезу в расположенной неподалеку скв. Кивиыли-8, описание разреза которой опубликовано (Рыымусокс, 1970 , с. $147-149$, рис. 28). Скв. Тыкке (Bekker, 1924, рис. 2, табл. 4; Левыкин, 1947 , с. 34 , рис. 2б) пробурена горным отделом Министерства торговли Эстонии в 1923, а скв. Камарику в 1925 г. (Рыымусокс, 1970, с. 153-154, рис. 29; Рыымусокс, 1960, рие. 26; Левыкин, 1947, c. 33). Керны этих скважин и оригиналы зарисовок разрезов скв. Тыкке и Камарику, выполненные А. Рейнвальдом в масштабе 1:20 (19231925), хранятся в Институте геологии АН ЭССР.

\section{Индексация слоев}

Сланценосные отложения кукрузеского горизонта отличаются от остальной части ордовика Эстонии исключительно дробной стратификацией, т. е. множеством слоев и пластов сланца-кукерсита. Их подавляющее большинство благодаря хорошей выдержанности может служить отличными стратиграфическими реперами, значение которых для детальной корреляции (синхронизации) разрезов и тем самым и для вскрытия внутренней структуры горизонта трудно переоценить. Для идентификашии кукерситовых слоев-реперов требуется единая индексация. Первая попытка в этом направлении была сделана в технических целях еще в прошлом веке А. Шамариным (Schamarin, 1870), который при описании разреза осушительной канавы у Кукрузе обозначил известняковые слои сверху вниз как A, B и D, а промежуточные между ними слои кукерсита как $\mathrm{A}^{\prime}$ (или II), $\mathrm{B}^{\prime}, \mathrm{C}$ и $\mathrm{C}^{\prime}$ (или IV-VI), D', E, E' и F (или VIII-XI) (см. также Погребов, 1919, рис. 2; Öpik, 1927, с. 16; 1928, с. 10; Рымусокс, 1970, с. 142).

В двадцатые годы текущего столетия почти одновременно возникли три системы индексации слоев кукрузеского горизонта по разрезу снизу вверх, а именно обозначения: 1) слоев промышленной пачки мелкими буквами латинского алфавита (Bekker, 1921, с. 15-20, рис. 5 и 7$)$; 2) слоев горизонта римскими цифрами от I до XXII (Bekker, 1924 , с. 4 , табл. 4 , рис. 2 ; Ӧріk, 1928, с. 10-11) и 3) кукерситовых слоев промышленной пачки горизонта заглавными латинскими буквами от А до Н, по системе индексации К. Лутса (Öpik, 1930, c. 23-24). В стратиграфическом отношении наиболее совершенна система индексации римскими цифрами Киршбаума-Беккера, но с 30-х годов на Эстонском месторождении стали общепринятыми буквенные индексы, предложенные K. Лутсом (Luha, 1946; Газизов, 1957; Бауков, 1973). $\mathrm{B}$ послевоенные годы эта индексация детализовалась $\left(\mathrm{A}, \mathrm{A}^{\prime}, \mathrm{F}_{1} \ldots \mathrm{F}_{5}\right)$, распространившись и на известняковые интервалы $\left(\mathrm{A} / \mathrm{A}^{\prime}, \mathrm{C} / \mathrm{D}, \mathrm{D} / \mathrm{E}\right.$ и др.) (Газизов, 1957; Котлуков, Бауков, 1968; Бауков и др., 1982). Данная система индексации кукерситовых и межкукерситовых слоев может быть с успехом продолжена вверх по разрезу с применением следующих .по алфавиту букв K, L и т. д. Впервые ее предложил, насколько нам известно, в конце 60 -х годов Р. Эйнасто при изучении кернов нескольких буровых скважин Әстонского месторождения. Буквенные индексы с указанными дополнениями приня̆ты для нижней половины сводного разреза кукрузеского горизонта и в настоящей статье (рис. 2); для индексации верхней половины разреза считаем целесообразным придерживаться уже укоренившейся в эстонской геологоразведочной практике системы римских цифр (снизу вверх I, II и т. д.), впервые введенной геологами Ә. Эрисалу, Т. Каттай и другими в конце 60 -х годов во время поисковых работ на Тапаском месторождении. В настоящей статье принят тот вариант системы индексации, 


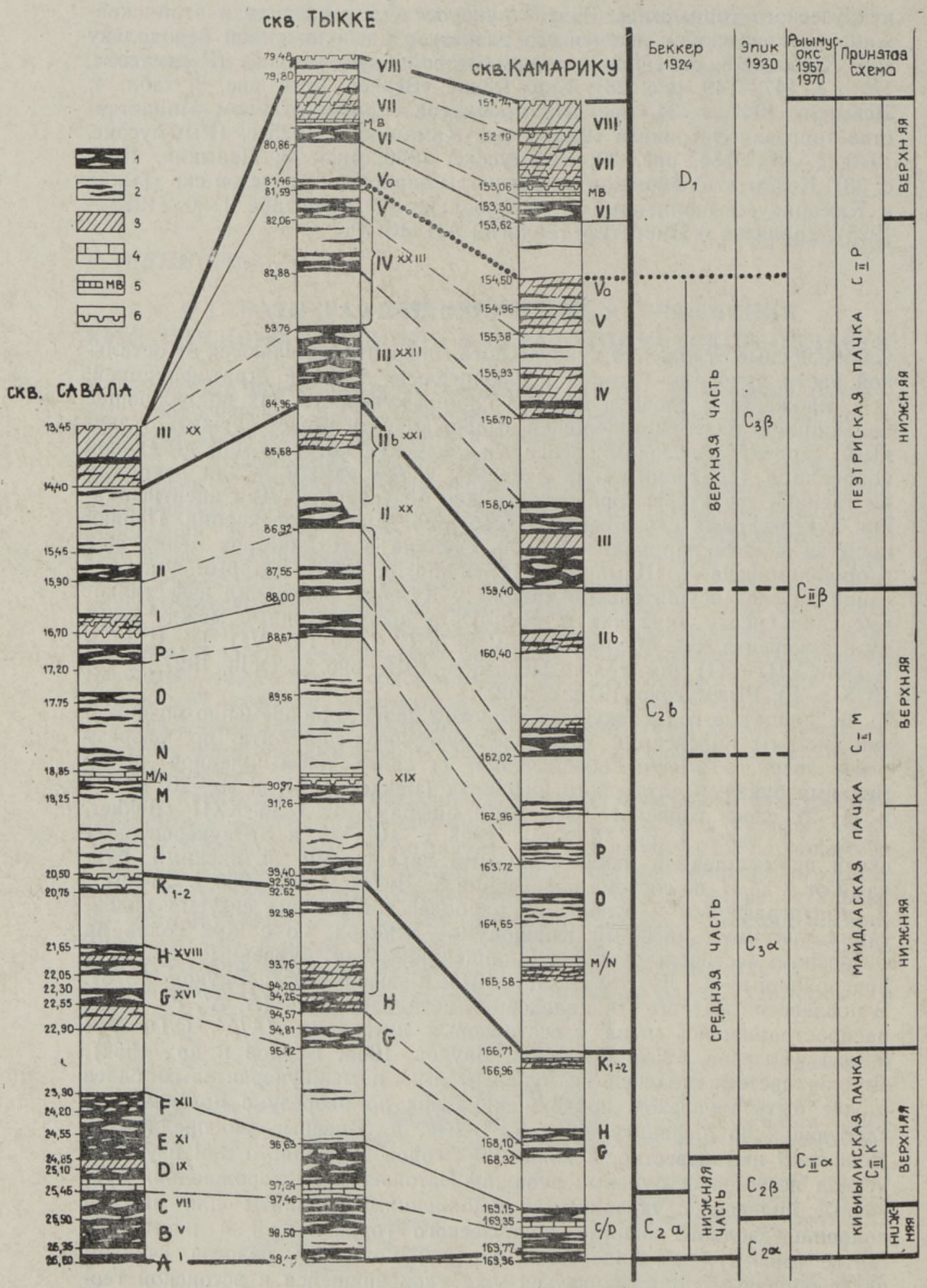

Рис. 2. Сопоставление выборочных буровых разрезов кукрузеского горизонта со стратиграфической разбивкой. Слева - северный, стратотипический стратиграфически сокращенный тип разреза (скв. Савала), справа - южные, более полно развитые разрезы (скв. Тыкке, Қамарику). Справа от колонок (указаны принятые индексы слоев (пластов), рядом - нндексы схемы Киршбаума-Беккера. 
согласно которому мощные сближенные пласты, залегающие над промышленным пластом III, обозначены как IV и V; индексом VI обозначен маломощный, но хорошо выдержанный пласт, непосредственно подстилающий интервал с маркирующим слоем бентонита; индексами VII и VIII обозначены комплексные пласты сложного строения, а, индексами IX и X - тонкие простые пласты самых верхов кукрузеского горизонта. Кроме того, выделен особый маломощный пласт Va, залегающий в кровле $\mathrm{V}$ пласта и имеющий реперное значение при корреляции по хитинозоям.

\section{Объем и границы}

Объем кукрузеского горизонта в сланценосной фации Северной Эстонии определяется в настоящее время интервалом от подошвы пласта А до кровли пласта X с той предпосылкой, что соответствующие границы биостратиграфически достаточно четки и широко прослеживаемы. Но указанные стратиграфические уровни в этом отношении еще мало изучены, микропалеонтологическая обоснованность принятых в настоящее время границ явно недостаточна и сами границы еще совсем недавно проводились в разных районах по-разному. Так, в районе, расположенном вблизи южной границы бассейна горючих сланцев в Центральной Эстонии, нижняя граница горизонта проводилась обычно на уровне появления в разрезе первых прослоев или примазок кукерсита, считавшихся одновозрастными со слоями промышленной пачки Северной Эстонии (скв. Эйамаа, гл. 210 м; Сарв, 1960; Рыымусокс, 1970; скв. Лаэва-297, гл. 263 м). Вследствие такой корреляции мы ошибочно понизили нижнюю границу кукрузеского горизонта в стратотипическом районе до основания эрраской пачки (Мянниль, 1966), в связи с тем, что в слоях Центральной Эстонии, залегающих ниже указанного уровня появления кукерсита, были обнаружены остракоды еще кукрузеского возраста (Мянниль, 1966). И только позже при корреляции по хитинозоям (об этом будет речь в специальной статье) выяснилось, что представление о сопоставимости уровня появления кукерсита в разрезах Центральной Эстонии и основания промышленной пачки Северной Эстонии ошибочно; в действительности кукерситы появляются в Центральной Эстонии на значительно более высоком стратиграфическом уровне, чем в северных районах.

В результате указанной неправильной трассировки нижней границы кукрузеского горизонта в работе Р. Мянниля $(1966$, с. 48 , рис. 17) эрраская пачка в разрезах Северной Эстонии ошибочно оказалась в составе кукрузеского горизонта, а в работе А. Рымусокса (1970, c. 119 , рис. 23) нижняя часть кукрузеского горизонта, мощностью 5,1-9,5 м, в южных разрезах (скв. Садала, гл. 213,15-219,70; скв. Кярде, гл. 207,7-214,1; скв. Козе, гл. 183,75-192,25; скв. Ныва, гл. $247,1-256,6$; скв. Эйамаа, гл. $210,49-215,67$ м) - ошибочно в составе ухакуского горизонта.

Проблема проведения верхней границы кукрузеского горизонта имеет иной характер, так как на севере, как это ныне установлено детальными микробиостратиграфическими исследованиями, этой границе соответствует значительный седиментационный перерыв и она

Справа приведены принятая в настоящее время схема расчленения отложений горизонта на пачки (Решения..., 1978) и на подпачки, а также сопоставление их с подразделениями ранее предложенных стратиграфических схем.

Границы пачек показаны жнрной, подпаче: - тонкой линией; жирным пунктиром показана верхняя условная граница горизонта, предложенная X. Беккером в 1924 г. I кукерсит с комками керогенсодержащего («розового») известняка, 2 линзы кукерсита, 3 ерозовый» известняк, 4 известняк маркирующего значения, 5 бентонит, 6 поверхность перерыва. 
проводится там поэтому однозначно и без особого труда (см. Рыымусoкc, 1970, с. 202-204; Nõlvak, 1972). В разрезах же Центральной Эстонии перерыва или по меньшей мере четкого перерыва нет и проведение границы зачастую условное. Так, в скв. Эйамаа (Сарв, 1960; Рымусокс, 1970 , с. 205) граница проводилась по прослою кукерсита (гл. 199,1 м), который, по хитинозоям, соответствует середине зоны Eremochitina dalbyensis и находится примерно на 2,5 м выше (по скв. Лаэва-13 даже 4,5 м выше) принятого нами основания идавереского горизонта. Точный уровень биостратиграфической границы кукрузеского и идавереского горизонтов в этом районе до сих пор еще не установлен, однако, согласно имеющейся микропалеонтологической информации, он, вероятно, находится вблизи слоя кукерсита X, вскрытого скважиной Эйамаа на гл. 201,83-201,96 м.

\section{Местные подразделения}

В сравнительно узкой полосе северной части сланцевого бассейна, охватывающей и район стратотипа, разрез кукрузеского горизонта стратиграфически сокращен и состоит из двух основных частей, которые первоначально обозначали (Bekker, 1924) как продуктивную (нижнюю, $\mathrm{C}_{2} \mathrm{a}$ ) и непродуктивную (верхнюю, $\mathrm{C}_{2} \mathrm{~b}$ ) части горизонта. Впоследствии на их основании разработали двучленное стратиграфическое деление горизонта на т. н. слои $\mathrm{C}_{2}$ и $\mathrm{C}_{3}$ (Öpik, 1927; Öpik. $1930 a$ ), а позже - на нижний (кохтлаский, $\mathrm{C}_{\amalg} \alpha$ ) и верхний (хумалаский, $\mathrm{C}_{\text {Ir }} \beta$ ) подгоризонты (Jaanusson, 1945; Рымусокс, 1957; Ры Рмусокс, 1970 и др.). Двучленное деление горизонта достаточно хорошо отражает строение его в районе стратотипа (рис. 1, разрез скв. Савала) (Bekker, 1924, рис. 2, разрез скв. Ярве; Рыымусокс, 1970, рис. 28, разрезы скв. Сомпа, Кивиыли, Тырма).

В южной, основной полосе бассейна стратиграфический объем геризонта более полный и его разрез слагается здесь по существу двумя (нижней и верхней) «продуктивными» толщами и промежуточной между ними «непродуктивной». Разрез такого типа в кукрузеском горизонте первоначально изучали в северо-западной части бассейна на выходах у Пеэтри (Погребов, 1919), но на востоке впервые установлен лишь после вскрытия бурением у хутора Тыкке (Bekker, 1924, pис. 2) (рис. 2). Учитывая этот южный, более полный тип разреза, $\mathrm{X}$. Беккер считал целесообразным и возможным подразделять кукрузеский горизонт (параллельно с двучленным его делением) на три части или соответственно на нижние, средние и верхние слои (Bekker, 1924 , с. 4,13 , табл. 4). Это предложение Х. Беккера в течение долгих лет не находило применения и было по существу забыто. Последовал ему лишь А. Эпик (Öpik, 1930в, с. 23), установив подразделения С и $\mathrm{C}_{3} \beta$ и приравняв их соответственно к средней и верхней частям горизонта схемы Х. Беккера. Только в конце $60-$ х годов в связи с развертыванием поисков горючих сланцев в верхней части горизонта на Тапаском месторождении, а также в связи со специальными литологостратиграфическими исследованиями Х. Стумбура и других, подразделение X. Беккера стало актуальным и нашло применение в стратиграфической практике. В частности, трехчленное деление отложений кукрузеского горизонта района сланцевого бассейна (Северная Эстония) вошло в стратиграфическую схему ордовикских отложений Прибалтики (Решения ..., 1978). Согласно этой схеме, кукрузеская часть вийвиконнаской сланценосной свиты сложена снизу вверх кивиылиской, майдлаской и пеэтриской пачками, формальная валидность которых основывается на публикациях А. Рыымусокса 1957-1970 гг. (см. Мян- 
ниль, Рыымусокс, 1984). В указанной схеме вийвиконнаская свита рассмотрена в широком объеме, включающем, кроме трех кукрузеских, эрраскую пачку ухакуского возраста и раннеидаверескую татрузескую пачку. Включение первой связано с тем, что ее сланценосность больше, чем в подстилающих отложениях, а по основанию этой пачки на Ленинградском месторождении по сей день проводится нижняя граница кукрузеского горизонта (Дубарь, Левин, 1973). Татрузеская пачка была включена в состав вийвиконнаской свиты лишь условно.

В свете новых данных о строении ухакуского, кукрузеского и идавереского горизонтов на территории Северной и Средней Эстонии представляется целесообразным рассматривать татрузескую пачку как самостоятельную свиту, а эрраскую как составную часть кыргекаллаской свиты, чтобы ограничить объем вийвиконнаской свиты лишь совокупностью кивиылиской, майдлаской и пеэтриской пачек в сланценосной фациальной зоне. ${ }^{1}$ Ниже кратко остановимся на вопросах стратиграфии этих трех пачек.

Кивиылиская пачка (С̈К) формально действительна с 1959 г., когда это название было предложено А. Рыымусоксом $(1959$, с. 22$)$ взамен мезофации Виру, выделенной им же двумя годами раньше как сланценосные отложения раннекукрузеского (кохтлаского) возраста (Рыымусокс, 1957 , с. 123-124). В качестве стратотипа может быть принят разрез заброшенного карьера. Кюттейыу, где полная мощность пачки 6,32 м (Рымусокс, 1970, с. 139-140).

Объем кивиылиской пачки близок объему нижних слоев кукрузеского горизонта в схеме Х. Беккера (1924), но включает также пласты $\mathrm{G}$ и $\mathrm{H}$ и слои интервала $\mathrm{H}-\mathrm{K}_{1-2}$ (рис. 2). Нижняя граница пачки и горизонта совпадает, а верхняя проводится в районе стратотипа по двойной поверхности перерыва (соответствует границе подгоризонтов по схеме А. Рымусокса), расположенной на 1,0-1,3 м выше пласта Н. Пограничная поверхность перерыва к югу и востоку исчезает, но соответствующий стратиграфический уровень может быть прослежен по маломощному, но относительно выдержанному пласту $\mathrm{K}_{2}$.

Қивиылиская пачка - наиболее детально изученная часть разреза горизонта. Нижняя половина ее сложена промышленной пачкой горючих сланщев (слои А... F ${ }_{2}$ Эстонского месторождения; см. Bekker, 1924; Левыкин, 1947; Газизов, 1957; Бауков, 1960 и др.), верхняя преимущественно глинистыми известняками, вмещающими менее мощные слои и пласты кукерсита $\mathrm{F}_{3} \ldots \mathrm{F}_{5}, \mathrm{G}, \mathrm{H}$ и $\mathrm{K}_{1-2}$. Эти два подразделения прослеживаются по всей площади. развития пачки и могут рассматриваться как нижне- и верхнекивиылиская подпачки.

Кивиылиская пачка прослеживается практически на всей территории Прибалтийского сланцевого бассейна, хотя верхняя ее граница по периферии бассейна постепенно теряет четкость и может быть проведена местами там лишь условно.

Мощность пачки, которая в центральной части сланцевого бассейна достигает 6,0-6,3 м (Рымусокс, 1970), к периферии резко убывает до 2,5-3 м (рис. 2). При этом уменьшается в основном мощность нижней подпачки.

Майдлаская пачка $\left(\mathrm{C}_{\mathrm{II}} M\right)$. Эта средняя пачка сланценосных отложений кукрузеского горизонта представляет собой преимущественно известняковую часть разреза, разделяющую нижнюю и верхнюю его части с развитыми в них кукерситовыми пластами промышленного значения.

1 Эти предложения как исправления к стратиграфической схеме 1976 г. были приняты пленумом Прибалтийской РМСК в декабре 1982 г. 
Рис. 3. Сопоставление принятых в настоящее время пачек отложений кукрузеского горизонта (K - кивиылиская, M майдлаская, Р - пеэтриская) с литологофациальными подразделениями схемы А. Рымусокса ( $\mathrm{C}_{\mathrm{II}} \alpha \mathrm{V}$ - Виру, $\mathrm{C}_{\mathrm{II}} \alpha \mathrm{Ha}-$ Харку, С ${ }_{\text {I }} \beta \mathrm{H}$ - Хумала, $\mathrm{C}_{\mathrm{II}} \beta \mathrm{S}$ - Caвала). За основу принята модель строения горизонта по широтному профилю Вазалемма-Сомпа (Рыымусокс, 1957, рис. 4). I границы подгоризонтов 110 А. Рыымусоксу, 2 метахронные границы пачек (мезофаций) по А. Рымусокеу, 3 изохронные границы принятых пачек.

Стратотип пачки - береговые обнажения на р. Пуртсе в д. Савала (вблизи Майдла), где пачка вскрывается на мощность 5,34 м, без верхов (Рыымусокс, 1970, с. 140-141). Майдлаская пачка приблизительно соответствует средним слоям кукрузеского горизонта в схеме Х. Беккера (Bekker, 1924), сложному сочетднию савалаской (на востоке) и нижней части хумалаской (в средней части Северной Эстонии), а также основной части харкуской мезофации фациальнолитостратиграфической схемы А. Рыымусокса (1957, рис. 4; 1960, рис. 27) (рис. 3). По стратотипу майдласкую пачку можно было бы считать синонимом савалаской мезофации или пачки (Рыымусокс, 1957; 1960 , с. 87), но по содержанию они различны.

Очевидно, при определении верхней границы майдлаской пачки целесообразнее исходить из наиболее четкого и выдержанного уровня увеличения сланценосности в разрезе (общий принцип), с учетом приоритета X. Беккера, который провел границу между средней и верхней частями горизонта по основанию выделенного им кукерситового слоя XX (Bekker, 1924, табл. 4, рис. 2), соответствующего в разрезе скважины Ярве, по современной индексации, пласту III, а в разрезах Арвила-Ратва и Тыкке - пласту II. Интервал II/III на значительной территории представлен детритовыми комковатыми известняками с примесью кукерсита, характерными для преобладающей части майдлаской пачки, а пласт III - основной в верхнем комплексе слоев горючих сланцев. На западе, в стратотипе пеэтриской пачки, последний пласт маркирует границу между нижнней (почти исключительно известняковой) и верхней (сланценосной) частями разреза кукрузеского горизонта. Все сказанное говорит в пользу условного проведения границы между майдлаской и пеэтриской пачками по основанию III пласта.

Майдлаская пачка как по литологическому характеру, так и по мощности - нанболее выдержанная часть кукрузеского горизонта. Мощность ее колеблется в рассматриваемых разрезах лишь в пределах $6,1-7,5$ м. Пачка может быть подразделена на нижне- и верхнемайдласкую подпачки, с границей, проводимой условно по основанию I пласта. Нижняя подпачка $(2,9-4,5$ м) включает слаборазвитые кукерситовые пласты $\mathrm{M}, \mathrm{N}, \mathrm{O}$ и $\mathrm{P}$ и выдержанные известняковые маркеры $\mathrm{M} / \mathrm{N}$ и $\mathrm{N} / \mathrm{O}$, верхняя подпачка $(3,2-3,5$ м) - кукерситовые пласты I и II и местами ряд дополнительных, а в качестве маркирующего известнякового слоя интервал $\mathrm{Ia} / \mathrm{II}$, характеризующийся специфической мелкокомковатой текстурой.

На южной и юго-западной окраинах сланцевого бассейна отложения майдлаской пачки, как и кивиылиской, теряют кукерситоносность и постепенно переходят в сравнительно однородные светло-серые или 
серые детритовые известняки, которые можно уже рассматривать как составную часть особой, безкукерситовой свиты данного горизонта.

Пеэтриская пачка $\left(\mathrm{C}_{\text {II }} \mathrm{P}\right)$ развита главным образом в южной полосе сланцевого бассейна. Максимального стратиграфического объема она достигает уже за пределами условных границ бассейна. Таким образом, в рассматриваемом нами реггоне верхи пачки разновозрастные: на севере они древнее, на юге моложе, и верхняя граница пачки, как и горизонта, определяется основанием вышележащего идавереского горизонта. Пачка выходит на поверхность в окрестностях Таллина, где имеется ее стратотип. В стратотипическом разрезе (обн. Пеэтри; см. Рымусокс, 1970 , с. $132-134$, рис. 27) к пачке относятся слои $1-13$, суммарной мощностью 4,2 м.

Пеэтрискую пачку, по аналогии с нижележащими, можно подразделить условно на две подпачки, нижняя из которых в окрестностях Вардья, Ярва-Яани и Тудулинна достигает полного развития. Она сложена кукерситовыми пластами III, IV и V и вмещающими их глинистыми известняками, общей мощностью около 6,5 м.

Верхняя подпачка, мощность которой в рассматриваемых нами скважинах лишь $1,4-1,9$ м, в данной полосе піредставляет собой в некоторой степени трансгрессивную часть верхов кукрузеского горизонта. Подпачка включает здесь лишь пласт VI и недоразвитые маломощные «хвосты» комплексных пластов VII и VIII, не имеющих промышленного значения. В промежутке между пластами VI и VII имеется тонкий (3-5 см) маркирующий прослой бентонита (рис. 2).

По имеющимся данным верхняя подпачка достигает максимального стратиграфического объема в Әстонии в районе скважин ЭйамааИмавере-Лаэва, где мощность ее 5,9-6,2 м.

\section{ЛИТЕРА Т У Р А}

Бауков С. С. Горючие сланцы. - В кн.: Геология СССР. T. XXVIII. Эстонская ССР. M., $1960,254-273$.

Бауков С. С. Кукерситы Эстонской ССР и Ленинградской области. - В кн.: Формацни горючих сланцев. Таллин, 1973, 17-38.

Бауков С., Морозов О., Тубли T. Закономерности изменения основных параметров промышленной пачки горючего сланца Эстонского месторождения. - Изв. АН ЭССР. Геол., 1982, 31, 140-145.

Дубарь Г. П., Левин А. С. Особенности геологического строения и изучения Ленинградского месторождения горючих сланцев. - В кн.: Формации горючих сланцев. Таллин, $1973,39-53$.

Газизов М. С. Некоторые данные о строении, составе и условиях образования горючих сланцев Эстонской ССР. Эстонское республиканское научно-техническое горное общество. - Техн. инф. бюлл., 1957, 1, 5-18.

Котлуков B. А., Бауков С. С. Прибалтийский бассейн. Сланценосные отложения: В кн.: Геология месторождений угля и горючих сланцев СССР. Т. II. М., $1968,56-72$.

Левыкин В. В. Горючие сланцы Прибалтики. Л.-М., 1947.

Млнниль Р. М. История развития Балтийского бассейна в ордовике. Таллин, 1966.

Млнниль P. М., Рыьыусокс А. К. Ревизия литостратиграфической схемы расчленения ордовика Северной Эстонии. - В кн.: Стратиграфия древнепалеозойских отложений Прибалтики. Таллин, 1984, 52-62.

Погребов Н. Ф. Прибалтийские горючие сланцы. Естественные производительные силы России. T. IV, вып. 20. Петроград, 1919, 288-323.

Решения межведомственного регионального стратиграфического совещания по разработке унифицированных стратиграфических схем Прибалтики, 1976. Л. 1978.

Рыььмусокс A. K. Стратиграфия кукрузеского горизонта ( $\left.\mathrm{C}_{\mathrm{II}}\right)$ Эстонской ССР. Уч. зап. ТГУ, 1957, вып, 46, 101-130.

Pыbıусокс A. Strophomenoidea ордовика и силура Эстонии. I. Род Sowerbyella Jones. - Уч. зап. ТГУ, 1959, вып. 75, 11-50.

Рыьмусокс А. К. Ордовикская система. - В кн.: Геология СССР. Т. XXVIII. Эстонская ССР. М., 1960, 55-113. 
Рыbцусокс $A$. Стратиграфия вируской и харьюской серий (ордовик) Северной Эิстонии. І. Таллин, 1970.

Сарв Л. И. Стратиграфическое распространение остракод ордовика Эстонской ССР. Тр. Ин-та геол. АН ЭССР, 1960, вып. V, 237-247.

Bekker, $H$. The Kuckers Stage of the Ordovician rocks of NE Estonia. - Acta et Comm. Univ. Tartuensis, A II, 1. Tartu, 1921.

Bekker, $H$. Möned uued andmed Kukruse lademe stratigraafiast ja faunast. - Acta et Comm. Univ. Tartuensis, A IV, 1. Tartu, 1924

Jaanusson, $V$. Uber die Stratigraphie der Viru- resp. Chasmopsserie in Estland. - Geol. Fören Förhandl. Bd. 67, H, 2. Stockholm, 1945, 212-224.

Luha, A. Eesti NSV maavarad. - Eesti NSV Tartu Riikliku Ulikooli geoloogilised tööd. 2. Tartu, 1946.

Nõlvak, $J$. Kukruse ja idavere lademe piirikihtide iseloomustus Lipu puurprofiilis. ENSV TA Loodusuurijate Seltsi aastaraamat. Tallinn, 1972, 61, 39-59.

Schamarin, A. Chemische Untersuchung des Brandschiefers von Kuckers. - Arch. Naturk. Liv-, Ehst- und Kurlands, Ser. 1, 5. Dorpat, 1870, 25-68.

Opik, A. Beiträge zur Kenntnis der Kukruse- $\left(\mathrm{C}_{2}-\right)$ Stufe in Eesti II. - Acta et Comm. Univ. Tartuensis, A XII, 3. Tartu, 1927.

Opik, A. Beiträge zur Kenntnis der Kukruse- $\left(\mathrm{C}_{2}-\mathrm{C}_{3^{-}}\right)$Stufe in Eesti III. - Acta et Comm. Univ. Tartuensis, A. XIII, 11. Tartu, 1928.

Opik, A. Brachiopoda protremata der estländischen ordovizischen Kukruse-Stuie. Acta et Comm. Univ. Tartuensis, A XVII, 1. Tartu, $1930 a$.

Opik, A. Aufriß und Aufbau der Kuckersit-Stufe. - Der estländische Brennschiefer. Reval, $1930 b, 12-28$.

Ннститут геологии

Академии наук Эстонской ССР

Поступила в редакцию 14/VII 1983

\section{R. MÄNNIL \\ KUKRUSE LADEME STRATIGRAAFILISEST LIIGESTUSEST TEMA STRATOTUOPSES PIIRKONNAS}

Pōlevkivibasseini kolme puurprofiili (Savala, Tōkke, Kamariku) näitliku võrdluse alusel on konkretiseeritud ja põhjendatud kukruse lademe kohalikku kolmikliigestust stratotüüpses piirkonnas ning ühtlasi esitatud vastavate stratigraafiliste üksuste (kiviōli, maidla ja peetri kihistiku) lühiiseloomustus. Lisaks on käsitletud kukersiidikihindite indekseerimist kogu lademe ulatuses ning kukruse lademe stratigraafilise mahu ja piiritlemise küsimusi uusimatest biomikrostratigraafilistest uurimustest lähtudes.

\section{R. MANNIL}

\section{ON THE STRATIGRAPHIC SUBDIVISION OF THE KUKRUSE STAGE IN THE STRATOTYPE AREA}

Up to 1976 the Kukruse Stage in the stratotype area was usually subdivided into two main parts resp. substages (Fig. 2; see also Рыымусокс, 1970). In the seventies a three-fold subdivision of the rocks into Kiviōli, Maidla and Peetri members, which roughly correspond to the lower, middle and upper parts of the stage according to H. Bekker (1924), was accepted. In the present paper the stratigraphy of these members is shortly reviewed on the basis of three earlier published boring sections (Savala, Tōkke, and Kamariku), the first of which represents the northern (stratotype) type of the sequence. In the latter the stage is represented only by lower members, the third one being developed in the area southwards (and westwards) of the stratotype. In this paper the symbols for all the main kukersite seams of the Kukruse Stage (in ascending order: A ... P, I- X) are determined and the stadial stratigraphic boundaries discussed, 